\title{
Evaluating the impact of books in Chinese Studies: A case study of books authored by UCLA scholars
}

\author{
Zequan Xiong ${ }^{1,2,3}$ and Yufeng Duan ${ }^{3 *}$ \\ ${ }^{1}$ Library, East China Normal University, 500 Dongchuan Road, Shanghai, 200241, CHINA \\ ${ }^{2}$ Institute for Academic Evaluation \& Development, East China Normal University, 500 \\ Dongchuan Road, Shanghai, 200241, CHINA \\ ${ }^{3}$ Faculty of Economics and Management, East China Normal University, \\ 500 Dongchuan Road, Shanghai 200241,CHINA \\ e-mail: zqxiong@library.ecnu.edu.cn; *yfduan@infor.ecnu.edu.cn (corresponding author)
}

\begin{abstract}
This study is the first comprehensive analysis to evaluate the impact of books in a particular field, namely, Chinese studies, authored by scholars at the University of California, Los Angeles (UCLA). Bibliometric and altmetric indicators were applied to evaluate the impact of books, and correlations between different indicators were analyzed using Spearman correlation coefficients. The results showed significant differences between impact ranks using both indicators. Bibliometric indicators, including citations, library holdings, and book reviews, mainly reflect the academic impact of books, while altmetric indicators, including Amazon sales and Goodreads ratings, mainly reflect the social impact of those books. The most influential books and scholars were obtained based on each of the two indicator types. This effort can benefit academic efforts to evaluate the impact of books using multiple indicators.
\end{abstract}

Keywords: Bibliometrics; Altmetrics; Book impact; Book evaluation; Chinese Studies.

\section{INTRODUCTION}

Books and scholarly journals are the primary research outputs in the arts, humanities, and social science disciplines (Kousha, Thelwall and Rezaie 2011), including in area studies. According to the 2014 UK Research Excellence Framework report, book submissions represented 55 percent of all submissions in the humanities, 33 percent in the arts, and 22 percent in the social sciences, while the proportion is only 0.5 percent in science, engineering, and medicine (Torres-Salinas, Robinson-Garcia and Gorraiz 2017). Despite the clear importance of books in arts, humanities, and social sciences, evaluating their impact is still a hard nut to crack. Peer review is still a major, effective procedure to assess the impact of books, but it is difficult to carry out on a large scale because books are typically more complex and much longer than journal articles and thus involve considerably more time and effort to evaluate. 
Since the foundation of the Science Citation Index (SCI) by Eugene Garfield in 1961, citation analysis has established its monopoly position for evaluating the impact of journals and their articles. The effectiveness of citation analysis mainly depends on the coverage and accuracy of citation index databases. Since books have been neglected in scientific assessment for a long time, book citation index databases are very rare. Even the Web of Science (WoS) and Scopus, the two largest citation index databases in the world, started collecting books only in recent years and in limited quantities (Gimenez-Toledo, Manana-Rodriguez and Sivertsen 2017; Gorraiz, Purnell and Glanzel 2013). This gap is obviously very unfavorable in the evaluation of research impact in the arts, humanities, and social sciences, where books are the main research output.

As against WoS and Scopus, Google Scholar can automatically extract citation data from a large number of journal articles and books using web crawlers, which would appear to make up for the deficiencies in the other databases in book citation data to some extent. Unfortunately, scholars have found that the automatic indexing done by Google Scholar inevitably includes some errors and can be manipulated easily (Labbé 2010); for example, a book with a short (e.g. one-word) title may be mistaken for other books with similar titles, causing a large degree of data deviation.

Meanwhile, citations cannot fully reflect the impact of all books, which is not expressed only in academic activities but also in teaching and public education. These impacts cannot be reflected by citation counts alone-for instance, some best-sellers often do not get cited in journal articles, although they have a high reputation in the public arena.

With the expansion of the Internet and digital platforms, some new indicators - usage metrics or altmetric indicators - can be used as supplements to traditional bibliometric indicators based on citation, and can reflect the impact of books from different perspectives. The purpose of this study in a specific area studies field, i.e. Chinese studies, is (a) to verify the effectiveness of various bibliometric and altmetric indicators for the evaluation of book impact and the relationships between different indicators, and (b) to establish a method that can be applied to the use of altmetric indicators to evaluate books on a large scale.

In a previous study, Chen and Wang answered the question of "who published what in East Asian studies" (Chen and Wang, 2008), but they did not address which of these books had greater academic and social impact and what the topics of these highly influential books were. Therefore, this study takes the subset of East Asian studies books i.e. those in Chinese studies, as a research sample to answer the following questions:

(a) Which books have greater academic impact or social impact in this study?

(b) Which topic in Chinese studies is taken up by studies with the greatest academic impact and social impact?

(c) Are the academic and social impact of books consistent? 


\section{LITERATURE REVIEW}

Citation-based indicators have been monopolizing academic book impact evaluation. Three databases were mainly used as data sources for citations: Book Citation Index (BKCl), Google Books, and Google Scholar. Kousha, Thelwall and Rezaie (2011) compared the citation counts of 1,000 books from Google Books and Google Scholar with Scopus citations and found that Google Books and Google Scholar citations were 1.4 and 3.2 times higher respectively than Scopus citations, which suggested that Google Books and Google Scholar could be the most appropriate data sources for book impact evaluation. However, Torres-Salinas et al. (2012) analyzed different impact indicators referred to the scientific publishers included in the $\mathrm{BKCl}$ for the social sciences and humanities fields during 2006-2011, and concluded that $\mathrm{BKCl}$ was not a reliable tool for bibliometric analysis since its limitations in coverage, for example, it only selected books from commercial English publishers. Later on, Torres-Salinas et al. (2014) analyzed disciplinary coverage of $\mathrm{BKCl}$ focusing on publisher presence, impact and specialization, and found that most of the disciplines were covered by very few publishers, mainly from the United Kingdom and the United States. What is more, $\mathrm{BKCl}$ did not retrieve all citations for books and chapters, and book citations did not include citations to their chapters. Abrizah and Thelwall (2014) analyzed the citations of books published by Malaysian university press using Google Books and Google Scholar and found that only a minority of the books had been cited. These studies proved that there were some defects in the book citation databases, and the citation data from them were not accurate enough to reflect the academic impact of books. Despite all this, the number of citations is still widely used in book impact assessment (Halevi, Nicolas and Bar-Ilan 2016; Mas-Bleda and Thelwall 2018; Kousha and Thelwall 2018; Tatalovich and Frendreis 2019; Jokić, Mervar and Mateljan 2019) because of its relevance to the academic impact of books.

Altmetrics are the product of the rise of the Internet and social media. It can directly reflect the degree of academic outputs concerned or used. The earliest empirical analysis of book impact using altmetric indicators was by Zuccala et al. (2015), who took 8,538 books published in the field of history as their study sample and found a weak correlation between citation counts and Goodreads reader rating counts. Kousha and Thelwall (2016b) found a low-to-moderate correlation between citations and Amazon reviews based on a set of 2,739 academic books and a set of 1,305 bestsellers. Torres-Salinas, Robinson-Garcia and Gorraiz (2017) calculated 18 indicators from altmetrics (such as Tweets and Facebook shares) to library holdings, views, downloads, and citations for books from a Spanish university using PlumX from EBSCO, and observed a low presence of altmetric indicators for books but a predominance of library holdings. The authors concluded that library holdings might be the most promising indicator towards the analysis of the impact of books. Wang, Liu and Han (2018) examined the feasibility of Goodreads reviews as an indicator of book impact assessment and concluded that key considerations in their use should include the subject discipline, the reviewer's role, and the sentiment polarity. Erfanmanesh, Noorhidawati and Abrizah (2019) assessed the impact of 1116 randomly selected books covering four broad disciplines (pure sciences, social sciences, engineering and medicine) 
using Bookmetrix. The results demonstrated that books in pure sciences got more citations, books in medicine received more social media attention, and engineering books had more download counts and Mendeley bookmarks.

\section{MATERIALS AND METHOD}

This study focuses on Chinese studies books, written in the English language, authored by scholars working at the University of California Los Angeles (UCLA). Chinese studies (or Sinology) is defined as the academic study of China, primarily that of the Chinese language, literature, culture, and history, and often refers to Western scholarship (Wikipedia 2018). Various bibliometric and altmetric indicators were applied to evaluate the impact of these books, and the correlations between different indicators were be analyzed. The research scheme is illustrated in Figure 1.

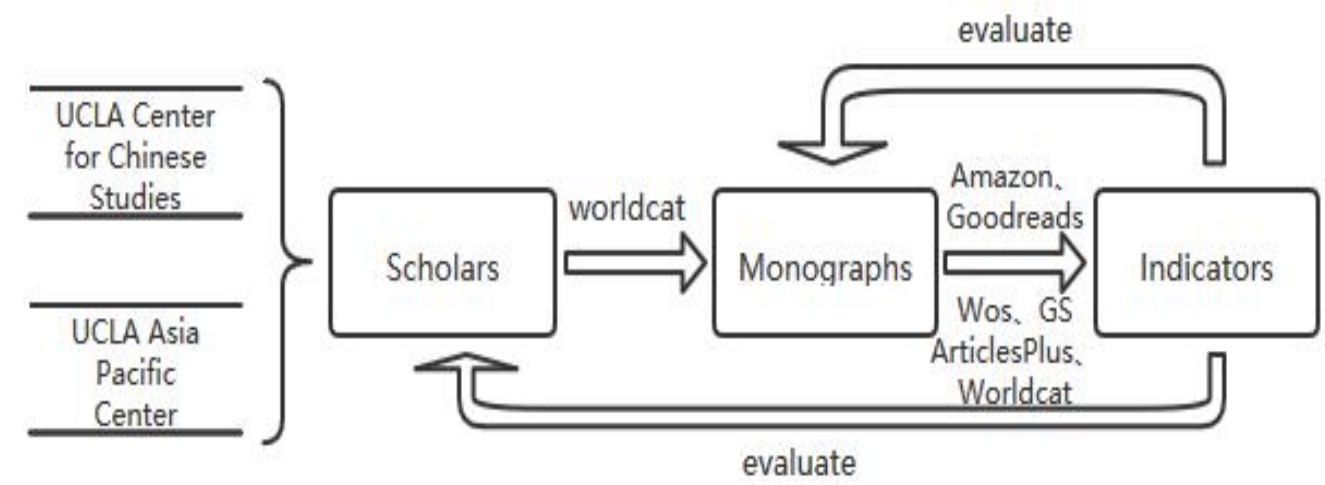

Figure 1: Research Scheme of this Study

The first step of this study was to determine the research materials i.e. which books should be included in this research. Thus, faculty lists were retrieved from the UCLA Center for Chinese Studies $^{1}$ and the UCLA Asia Pacific Center, ${ }^{2}$ followed by de-duplication and removal of adjunct scholars and scholars whose research areas were not related to the humanities, arts and social sciences. After obtaining a list of 45 UCLA scholars with research or teaching interests in Chinese Studies, the advanced retrieval function of OCLC WorldCat (the largest library catalog in the world) was applied to obtain books authored by the 45 scholars. In this step, the author and subject ("China" or "Chinese") fields were used as retrieval, and the document type was limited to "books." The information retrieved include title, author(s), publication year, publisher, edition, ISBN, and library holdings for each monograph.

\footnotetext{
1 http://www.international.ucla.edu/ccs/about

2 http://www.international.ucla.edu/apc/people/china
} 


\section{Impact Indicators}

After book list was obtained, the next step is to choose appropriate impact indicators for impact evaluation. Among the many possible indicators, such as citations, downloads, Amazon mentions, and Mendeley readers, not all are suitable for the evaluation of books because of data unavailability. This section introduces the main impact indicators used in this research and explain the reasons for selecting them.

(a) Citations: Citations are the number of times that a book or chapter has appeared in the reference lists of other articles and books. As a traditional bibliometric indicator, citation is often used to evaluate the academic impact of journal articles; after the introduction of $\mathrm{BKCl}$ and other book index databases, citations were also gradually applied to the academic impact evaluation of books. However, there are still issues with using citations to evaluate the impact of books; for example, some databases neglect citations of chapters of a book, leading to the deviation between the data and the actual number of citations. Nevertheless, citations embody the recognition by the academic community of the academic value of books.

(b) Book Reviews: A book review is a form of literary criticism in which a monograph is analyzed based on content, style, and merit by a peer reviewer. In the United States, pre-publication peer review is an important process to assess the value of books in humanities and social sciences disciplines. Often, two or more reputable scholars in a particular field will be invited by publishers to assess and determine whether a proposed monograph should be published or not, with areas for modification and needed changes. After a monograph is published and makes its way to the book market, one or more book reviews are often written by invited scholars in relevant fields or volunteer scholars who consider the book to be valuable. These are published in disciplinary journals. These book reviews often extend the book's readership beyond disciplinary boundaries. Therefore, the number of book reviews can be a direct reflection of academic impact.

(c) Library Holdings: Library holdings are the number of libraries that own ("hold") a book. Such data can be derived from national or international union library catalogues, such as WorldCat. However, library holdings cannot reveal if, how, how often, or by whom a book is used, and thus only provide a limited understanding of historical impacts on such areas such as teaching and research-even more so because less current materials are often weeded from library collections. However, library holdings might reflect the educational value or cultural influence of books, which are not really captured by citation-based indicators. Thus, this indicator was considered the most promising one for the analysis of the impact of books (Torres-Salinas, Robinson-Garcia and Gorraiz (2017), especially in the social sciences and humanities (Torres-Salinas and Moed 2009).

(d) Altmetrics: The term altmetrics was proposed by Jason Priem (Priem et al. 2010) to indicate an alternative or complement to traditional citation impact metrics. Altmetrics are primarily based on data from non-academic literature, such as citations on Wikipedia, references in public policy documents, discussion on research blogs, mainstream media 
coverage, bookmarks on reference managers like Zotero or Mendeley, mentions on social networks such as Twitter, scores on Goodreads, or sales data on Amazon. These indicators, to a certain extent make up for the shortcomings of traditional bibliometric indicators, such as deviation in different subjects and time lag. In this study, altmetric indicators from Amazon and Goodreads were chosen to evaluate the social impact of books, because of the highly comprehensive coverage of books on these two platforms.

(e) Other Indicators: Book award records and book lending counts in certain libraries are also useful indicators in the evaluation of books. Many professional societies have specific awards that reflect the recognition by peers of winning books. However, awards are often published only on certain websites in news articles or even made inaccessible to the public, making practical application very difficult, whereas book lending counts only reflect the reading tendency in a specific library. There may be a large discrepancy in this regard between different libraries that prevents book lending counts from capturing the full impact of a book. Therefore, these two indicators are not included in this study.

\section{Data Sources}

Impact indicators were collected from multiple databases, as follows:

(a) Citations: Two databases, Google Scholar and WoS, are used as data sources for citation counts. Google Scholar has comprehensive citation data, while WoS has relatively high quality citation data; therefore, both the quantity and quality of book citations can be reflected.

(b) Book reviews: UCLA's ArticlesPlus was used to collect reviews for each book as comprehensively as possible. ArticlesPlus is powered by the Summon search engine from ProQuest. It searches millions of journal and newspaper articles, e-books, government documents, and more, drawing full-text articles from databases including JSTOR and WoS, as well as digital repositories and other open-access archives on the web. Although the results are comprehensive, duplicate statistics may exist because of inclusion in different databases. Therefore, after retrieving and downloading book reviews according to book title and publication year, duplicate records were removed manually before analysis.

(c) Library holdings: The library holdings of each monograph were first collected using WorldCat. It should be noted that when one book was issued in different editions, multiple records would be found in WorldCat, but the library holdings of these records would be merged. Figure 2 shows an example of the book China on the Move: Migration, the State, and the Household, by C. Cindy Fan (published by Routledge in 2014); when we clicked "view all formats and versions," 13 different records were listed, under multiple ISBNS, and the library holdings were 302 altogether.

(d) Altmetrics: This study adopted Amazon and Goodreads, the largest online bookstore and the largest book reviews website in the world, respectively, as databases. Amazon metrics (Amazon reviews, Amazon stars, Amazon sells rank) and Goodreads metrics (Goodreads reviews, Goodreads stars, Goodreads ratings) for each book were collected for this investigation. 


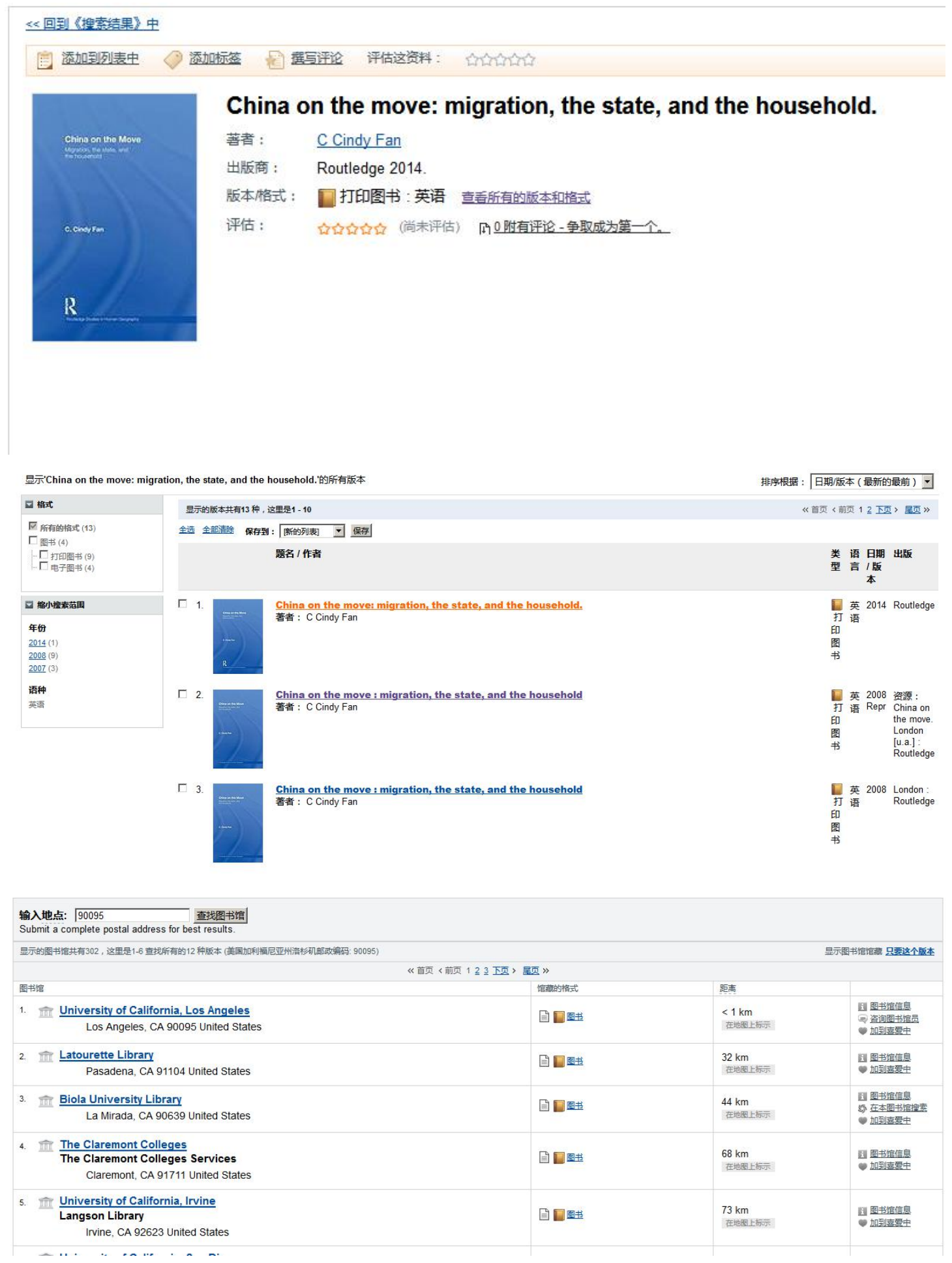

Figure 2: Library holdings of One Book with Different Formats and Versions, Merged in WorldCat: China on the Move: Migration, the State, and the Household, by C. Cindy Fan Published by Routledge in 2014

\section{Data Analysis}

After obtaining all indicators for each book, Microsoft Excel spreadsheet was used to carry out a descriptive analysis on the dataset. In the impact analysis, this study assumed that 
the numbers of book reviews, library holdings, and citations all reflect academic impact while Amazon metrics and Goodreads metrics reflect the social impact of books. The correlations for all indicators were analyzed by the Spearman correlation coefficient using IBM SPSS Statistics 23.

\section{RESULTS}

\section{Descriptive Analysis}

In all, 77 books authored by 28 UCLA scholars in Chinese Studies were obtained from WorldCat; the other 27 scholars had not produced any monograph related to Chinese Studies. The years of publication of these 77 books spanned from 1971 to 2017, and the years with the highest yield ( 6 books published) were 2009 and 2011 (Figure 3).

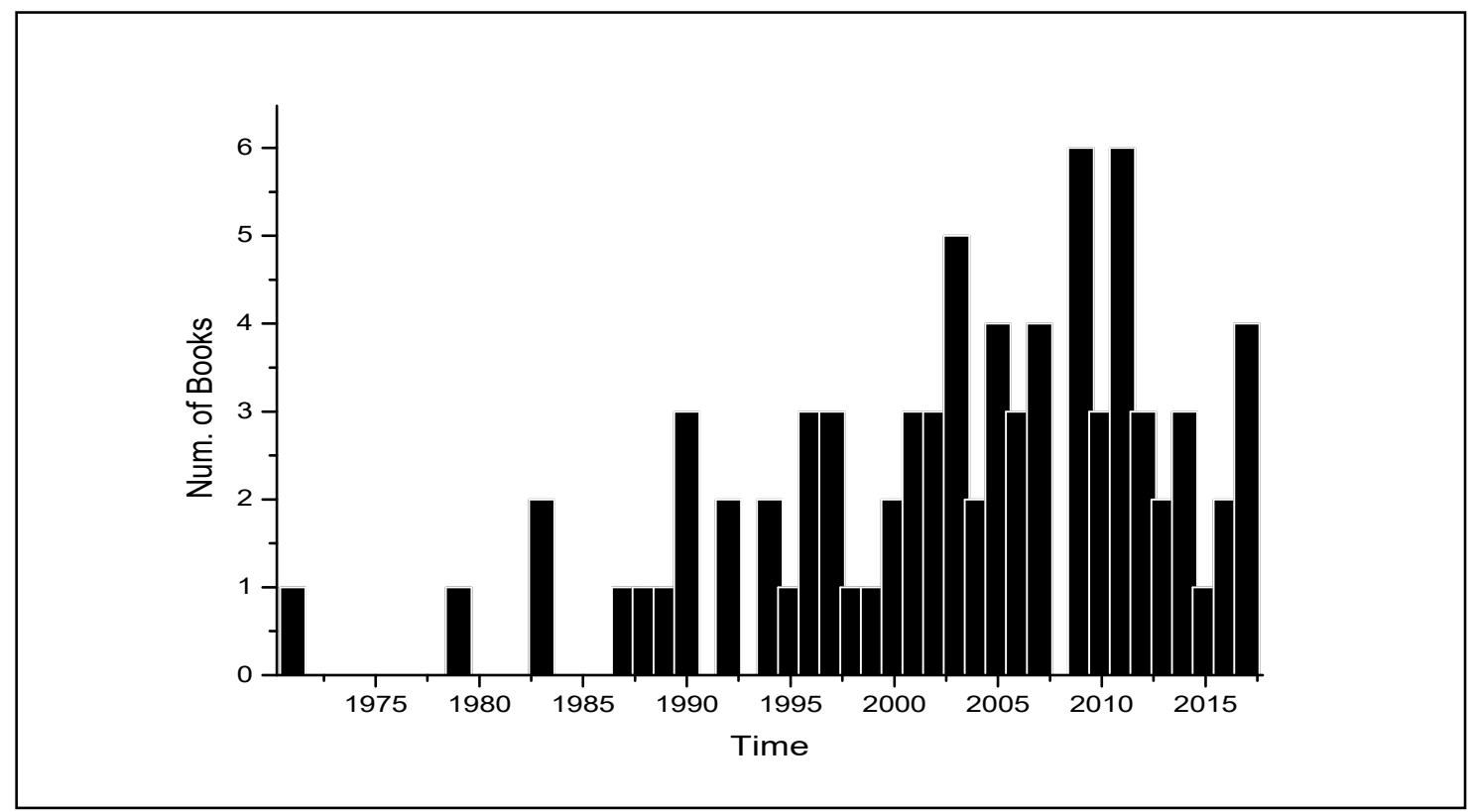

Figure 3: Distribution of Years of Publication of Books in This Study

\section{Academic Impact of Books}

According to Clarivate Analytics, WoS covers the world's top tier international and regional journals, whose evaluation and selection is governed by the WoS core collection journal selection process, a well-established set of criteria. Thus, it is believed that only high-quality books will be indexed or cited in the WoS Book Citation Index, which has more than 60,000 books. In this study, only 8 books were indexed in WoS, accounting for 10 percent of the total sample; however, there were 54 books cited more than once in WoS-indexed sources, accounting for 68.4 percent of the total sample, of which the most cited was The Learning Gap: Why Our Schools Are Failing and What We Can Learn from Japanese and Chinese Education, written by James W. Stigler in 1992 and consulted by scholars in American Studies, Chinese Studies, Japanese Studies, and Education. Of its 470 citations, 184 came from educational journals; what is more, these 184 citing articles then obtained an extra 15000 citations, which further expanded the impact of this book. From 
the citation tendency chart (Figure 4), we see that citations of The Learning Gap showed a fluctuating upward trend from its publication year to 2017, and it was expected to get about 30 citations in WoS in 2018. At the same time, this book had been cited 2602 times in Google Scholar, which was the highest citation count in this study and shows a very high impact in academia.

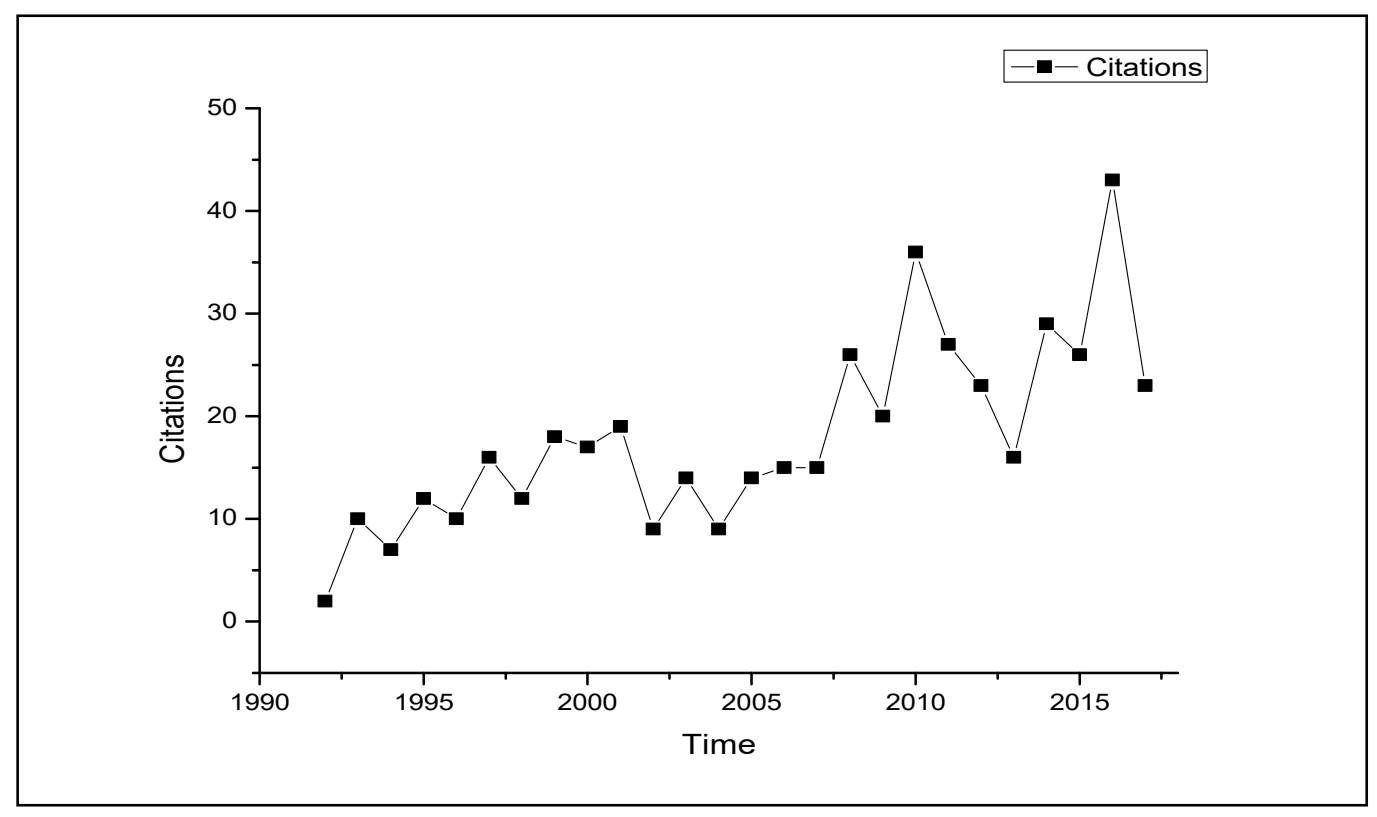

Figure 4: Citation Tendency for The Learning Gap: Why Our Schools Are Failing and What We Can Learn from Japanese and Chinese Education

Whether a book receives a book review in the early stages after publication is an important factor related to its future impact, in that it reflects the degree to which the book is approved by peers. In this study, book reviews for each of the 77 books retrieved from WoS and Google Scholar indicated that 49 books had reviews in WoS and 41 in Google Scholar. When searching in ArticlesPlus, however, 63 books had received book reviews, accounting for 80 percent of the dataset. This gap suggests that ArticlesPlus collects book reviews more comprehensively than WoS and Goggle Scholar, and thus ArticlesPlus was adopted as the data source for book reviews.

The book that received the most book reviews was Private Life Under Socialism: Love, Intimacy, and Family Change in a Chinese Village, 1949-1999, authored by Yunxiang Yan in 2003. This book also received 254 citations in WoS, ranking it 6th in the dataset and 2nd among books published after 2000 in the dataset. Meanwhile, the library holdings for this book were 1,945, meaning it ranked third in the dataset and second in the books published after 2000 in the dataset. These data indicate that this book is in the active period of its life cycle and that its indicators still have a lot of room to increase.

Only 1 of the 77 books had no library holding record in WorldCat. At the other end, the book entitled The Sinister Way: The Divine and the Demonic in Chinese Religious Culture, 
written by Richard von Glahn in 2004, had the most library holdings (2113). This monograph is a study of features of Wutong, the preeminent god of wealth in late imperial China. It is noteworthy to point out that high holdings do not imply that citation counts or sales will be equally high; for Glahn's book they were in the midrange among the 77. Why then was this book on religious education accessioned and kept in the active collection by so many libraries? It deserves further study.

\section{Social Impact of Books}

Three books did not have any record in Amazon, and 35 books had not receive any Amazon stars or reviews. Only 40 books had received both stars and reviews, of which 34 books received 4 stars or more, accounting for 43 percent of the dataset. Further, 19 books had received 5 stars; of these, the one with the most citations was The Individualization of Chinese Society, authored by Yunxiang Yan in 2009. In addition, this book's sales were the highest among the 5-star books. The earlier mentioned metrics indicate that this book was not only well recognized by scholars but also popular among general readers. However, the citation counts and library holdings of other 5 -star books were poor.

Some indicators for 5-star books are shown in Table 1. It is worth noting that most of the 5 -star books had received only one Amazon review and thus their star rating might fluctuate with time. For example, a 5-star book with one review might become a 2.5-star book if it gets 1 star from the next reviewer. Indeed, we found that most books had received few reviews. Although To Live: $A$ Novel authored by Michael Berry, had received 80 reviews, which ranks first in the dataset, the book ranked second dropped to only 16 reviews, and more than 25 percent of the books had just had one review in Amazon.

Five books did not have any record in Goodreads, and 19 books had received zero Goodreads stars or ratings. Moreover, 42 books had no Goodreads reviews (including the above 19 books), accounting for 53.2 percent of our dataset. There were 27 books that had received 4 stars or above on Goodreads, while only 14 had received 4 stars or above on Amazon; only 2 books received 5 stars in both websites. The book that had received the most Goodreads reviews, 464 times, was To Live: A Novel, by Michael Berry, which had also received the most reviews in Amazon. 
Evaluating the Impact of Books in Chinese Studies

Table 1: Library Holdings, WoS Citations and Amazon Reviews of 5-Star Books

\begin{tabular}{|c|c|c|c|c|c|}
\hline Book title & Author (s) & $\begin{array}{l}\text { Publication } \\
\text { year }\end{array}$ & $\begin{array}{l}\text { WorldCat } \\
\text { holdings }\end{array}$ & $\begin{array}{l}\text { WoS } \\
\text { Citations }\end{array}$ & $\begin{array}{l}\text { Amazon } \\
\text { reviews }\end{array}$ \\
\hline $\begin{array}{l}\text { Opera and the City: The Politics of Culture in } \\
\text { Beijing, 1770-1900 }\end{array}$ & Andrea Goldman & 2012 & 1621 & 0 & 1 \\
\hline $\begin{array}{l}\text { A Patterned Past: Form and Thought in Early } \\
\text { Chinese Historiography }\end{array}$ & David Schaberg & 2002 & 538 & 53 & 1 \\
\hline $\begin{array}{l}\text { Exquisite Moments: West Lake \& Southern } \\
\text { Song Art }\end{array}$ & Huishu Li & 2001 & 141 & 1 & 1 \\
\hline $\begin{array}{l}\text { Idle Talk: Gossip and Anecdote in Traditional } \\
\text { China }\end{array}$ & $\begin{array}{l}\text { Jack W Chen; } \\
\text { David Schaberg }\end{array}$ & 2013 & 119 & 0 & 1 \\
\hline $\begin{array}{l}\text { Suspended Music: Chime Bells in the Culture } \\
\text { of Bronze Age China }\end{array}$ & $\begin{array}{l}\text { Lothar von } \\
\text { Falkenhausen }\end{array}$ & 1994 & 1542 & 35 & 1 \\
\hline Wild Kids: Two Novels about Growing Up & Michael Berry & 2002 & 542 & 1 & 1 \\
\hline $\begin{array}{l}\text { Contemporary Chinese America: Immigration, } \\
\text { Ethnicity, and Community Transformation }\end{array}$ & Min Zhou & 2009 & 944 & 83 & 1 \\
\hline $\begin{array}{l}\text { The Accidental Sociologist in Asian American } \\
\text { Studies }\end{array}$ & Min Zhou & 2011 & 12 & 0 & 1 \\
\hline $\begin{array}{l}\text { Illusory Abiding: The Cultural Construction of } \\
\text { the Chan Monk Zhongfeng Mingben }\end{array}$ & Natasha Heller & 2014 & 183 & 5 & 1 \\
\hline Enlightening Remarks on Painting by Shih-t'ao & $\begin{array}{l}\text { Richard E } \\
\text { Strassberg; } \\
\text { Shitao (Shih-t'ao) }\end{array}$ & 1989 & 2 & 1 & 2 \\
\hline The Economic History of China: From & Richard von & 2016 & 275 & 2 & 4 \\
\hline Antiquity to the Nineteenth Century & Glahn & & & & \\
\hline $\begin{array}{l}\text { Fountain of Fortune: Money and Monetary } \\
\text { Policy in China, 1000-1700 }\end{array}$ & $\begin{array}{l}\text { Richard von } \\
\text { Glahn }\end{array}$ & 1996 & 1607 & 13 & 1 \\
\hline $\begin{array}{l}\text { China's Rising Research Universities: A New } \\
\text { Era of Global Ambition }\end{array}$ & Robert A Rhoads & 2014 & 536 & 20 & 1 \\
\hline Currents and Countercurrents: Korean & & & & & \\
\hline $\begin{array}{l}\text { Influences on the East Asian Buddhist } \\
\text { Traditions }\end{array}$ & Robert E Buswell & 2005 & 280 & 8 & 2 \\
\hline $\begin{array}{l}\text { The Formation of Ch'an Ideology in China and } \\
\text { Korea: The Vajrasamadhi-Sutra, a Buddhist } \\
\text { Apocryphon }\end{array}$ & $\begin{array}{l}\text { Robert E Buswell, } \\
\text { Jr. }\end{array}$ & 2017 & 415 & 0 & 1 \\
\hline Chinese Looks: Fashion, Performance, Race & Sean Metzger & 2014 & 952 & 12 & 1 \\
\hline The Individualization of Chinese Society & Yunxiang Yan & 2009 & 243 & 141 & 1 \\
\hline
\end{tabular}

There were 4 books published in 2017, Remains of Life: A Novel, by Michael Berry; The Formation of Ch'an Ideology in China and Korea: The Vajrasamadhi-Sutra, a Buddhist Apocryphon, by Robert Buswell; The Specter of Global China: Politics, Labor, and Foreign Investment in Africa, by Ching Kwan Lee; and Contemporary Chinese Diasporas, by Min Zhou. Although these four books were published only quite recently, their strong impact 
was revealed in many areas: the citation counts for The Formation of Ch'an Ideology in Google Scholar had reached 93 and that for The Specter of Global China, 58; the sales ranking of the latter on Amazon was also 135,067th, the second-best-selling book in the dataset. It is noteworthy that the library holdings for this highly impactful book are only 5 ; this phenomenon may be due to the intricate purchase and cataloging flow in libraries, which may result in time lag for some high-demand books. This also suggests that library resources procurement can usefully refer to data like citation counts on Google Scholar or sales ranking on Amazon for newly published books.

Overall, based on the above results, To Live: A Novel, by Michael Berry, was the book that had the greatest social impact.

\section{Correlation Analysis}

The Economic and Social Research Council defines research impact as "the demonstrable contribution that excellent research makes to society and the economy" (Economic and Social Research Council 2018). It considers impact to include both academic impact and socioeconomic impact. For journal articles, their effectiveness mainly means advancing scientific knowledge, method, theory, and applications across and within disciplines, that is, academic impact. For books, effectiveness is not only reflected in academic impact but also in impact such as on popularization of science and entertainment, which should be included in social impact. Therefore, evaluating the impact of books should consider both academic impact and social impact. As we know, while citation is an important indicator of academic impact, for social impact there are no authoritative indicators yet. Thus, this study conducted a correlation analysis using several indicators to explore their respective roles in impact evaluation.

The correlation coefficients between the indicators are shown in Table 5 . There is a significant strong correlation between citation counts in WoS (and also Google Scholar) and the number of book reviews (correlation coefficient $>0.600$ ), which suggests that these indicators have a consistent effect reflecting the academic impact of books. Moderate correlations were found between citation counts and library holdings, sales rank, reviews, and scores on Goodreads or Amazon, showing that these indicators may reflect the other perspective of the impact of books. For example, library holdings may reflect the impact of a book in culture and education (White et al. 2009; Kousha and Thelwall 2016a), while sales rank on Amazon or Goodreads scores shows the extent to which the books are welcomed by general readers, that is, their social impact. There is no significant correlation between citation counts and Amazon stars or reviews. This may be because Amazon is a sales platform, and its ratings and comments may be affected by non-content factors such as the quality of custom service, printing, book cover designs, and/or illustrations. Thus, Amazon metrics may not be suitable as a direct indicator of impact. 
Table 2: Correlation Coefficients between Different Indicators

\begin{tabular}{|c|c|c|c|c|c|c|c|c|c|c|}
\hline Indicators & $\begin{array}{l}\text { Library } \\
\text { holdings }\end{array}$ & $\begin{array}{c}\text { WoS } \\
\text { Citations }\end{array}$ & $\begin{array}{l}\text { Google } \\
\text { Scholar } \\
\text { Citations }\end{array}$ & $\begin{array}{c}\text { Book } \\
\text { reviews }\end{array}$ & $\begin{array}{c}\text { Amazon } \\
\text { stars }\end{array}$ & $\begin{array}{l}\text { Amazon } \\
\text { reviews }\end{array}$ & $\begin{array}{c}\text { Amazon } \\
\text { sellers } \\
\text { rank }\end{array}$ & $\begin{array}{c}\text { Goodreads } \\
\text { stars }\end{array}$ & $\begin{array}{c}\text { Goodreads } \\
\text { ratings }\end{array}$ & $\begin{array}{c}\text { Goodread } \\
\text { s reviews }\end{array}$ \\
\hline $\begin{array}{l}\text { Library } \\
\text { holdings }\end{array}$ & / & $.580^{* *}$ & $.636^{* *}$ & $.658^{* *}$ & .183 & $.377^{* *}$ & $-.411^{* *}$ & $.362^{* *}$ & $.534^{* *}$ & $.453^{* *}$ \\
\hline $\begin{array}{l}\text { Citations } \\
\text { in wos }\end{array}$ & $.580^{* *}$ & / & $.797^{* *}$ & $.607^{* *}$ & .050 & .189 & $-.325^{* *}$ & $.242^{*}$ & $.424^{* *}$ & $.230^{*}$ \\
\hline $\begin{array}{l}\text { Citations } \\
\text { in GS }\end{array}$ & $.636^{* *}$ & $.797^{* *}$ & / & $.718^{* *}$ & .133 & $.319^{* *}$ & $-.451^{* *}$ & $.341^{* *}$ & $.488^{* *}$ & $.291^{*}$ \\
\hline $\begin{array}{l}\text { Book } \\
\text { reviews }\end{array}$ & $.658^{* *}$ & $.607^{* *}$ & $.718^{* *}$ & / & .174 & $.265^{*}$ & $-.292^{*}$ & $.242^{*}$ & $.396^{* *}$ & $.255^{*}$ \\
\hline $\begin{array}{l}\text { Amazon } \\
\text { stars }\end{array}$ & .183 & .050 & .133 & .174 & / & $.792^{* *}$ & $-.488^{* *}$ & .191 & $.344^{* *}$ & $.363^{* *}$ \\
\hline $\begin{array}{l}\text { Amazon } \\
\text { reviews }\end{array}$ & $.377^{* *}$ & .189 & $.319^{* *}$ & $.265^{*}$ & $.792^{* *}$ & / & $-.677^{* *}$ & $.313^{* *}$ & $.640^{* *}$ & $.601^{* *}$ \\
\hline Amazon & & & & & & & & & & \\
\hline $\begin{array}{l}\text { sellers } \\
\text { rank }\end{array}$ & $-.411^{* *}$ & $-.325^{* *}$ & $-.451^{* *}$ & $-.292^{*}$ & $-.488^{* *}$ & $-.677^{* *}$ & I & $-.538^{* *}$ & $-.774^{* *}$ & $-.639^{* *}$ \\
\hline $\begin{array}{l}\text { Goodreads } \\
\text { stars }\end{array}$ & $.362^{* *}$ & $.242^{*}$ & $.341^{* *}$ & $.242^{*}$ & .191 & $.313^{* *}$ & $-.538^{* *}$ & / & $.618^{* *}$ & $.418^{* *}$ \\
\hline $\begin{array}{l}\text { Goodreads } \\
\text { ratings }\end{array}$ & $.534^{* *}$ & $.424^{* *}$ & $.488^{* *}$ & $.396^{* *}$ & $.344^{* *}$ & $.640^{* *}$ & $-.774^{* *}$ & $.618^{* *}$ & / & $.812^{* *}$ \\
\hline $\begin{array}{l}\text { Goodreads } \\
\text { reviews }\end{array}$ & $.453^{* *}$ & $.230^{*}$ & $.291^{*}$ & $.255^{*}$ & $.363^{* *}$ & $.601^{* *}$ & $-.639^{* *}$ & $.418^{* *}$ & $.812^{* *}$ & I \\
\hline
\end{tabular}

**Correlation is significant at the 0.01 level (2-tailed); *Correlation is significant at the 0.05 level (2-tailed).

\section{DISCUSSION}

Unlike other macro studies using big datasets to assess the effectiveness of citations or altmetric indicators, this study focused on a small dataset, taking a micro perspective. As a result, the reasons for deviation or consistency between citations and altmetric indicators can be deeply considered. As the results show, the books have different impact rankings when using different indicators. Some books showed high counts of Amazon and Goodreads reviews with low citations, such as To Live: A Novel. Conversely, books with high citations but low Amazon and Goodreads reviews (and other altmetric indicators) were also detected in this study, such as the three books of Ching Kwan Lee. This diversity suggests that there are two important aspects of the impact of books in the social sciences, i.e. academic impact and social impact. Therefore, in the evaluation of the impact of books, these two aspects should be considered comprehensively. 
Studies on the content and research fields of research books and their writers have found that the academic discipline their topic falls into may be one of the reasons for impact difference. Although this research was limited to Chinese Studies, this is a multi-disciplinary field, overlapping with anthropology, archaeology, art, geography, history, law, linguistics, literature, politics, sociology and other disciplines in a Chinese context. As literature plays a more important role in mass education and cultural popularization, and its academic contribution is weaker, its citation counts are also lower, while its reviews, sales, and other altmetric indicators are relatively higher. In contrast, some books with a strong theoretical nature and a certain reading threshold in terms of technical background are seldom read by the public, only by specialists. The effectiveness of these books is mainly reflected in how well they promote the development of theory, methods, and other aspects of the research field, as reflected through citations and other indicators. Therefore, in the large-scale evaluation of multi-disciplinary books, researchers should take disciplinary differences into account and should not generally adopt a single indicator for cross-disciplinary comparison.

In addition, this study finds that, compared with the traditional bibliometric indicators, the coverage of altmetric indicators is relatively low. For example, five of the present books were unrecorded on Goodreads, whereas Goodreads stars and ratings of 19 additional books were both zero. Meanwhile, the correlations among altmetric indicators offered through different platforms were not high. Rankings on commercial platforms such as Amazon may be influenced by non-book factors such as physical quality of papers, distribution services, and so on, while book reviews may also be negative. Therefore, if researchers use altmetric indicators to evaluate social impact, it is better to use an altmetric score, which is a comprehensive evaluation indicator for the impact of papers published by altmetric.com, for reference and to adopt multiple data sources to establish a comprehensive evaluation system.

\section{ACKNOWLEDGMENTS}

The authors are grateful to Su Chen, the Head of the East Asian Library, University of California, Los Angeles (UCLA), and Heather Briston, the Head of Curators and Collections and UCLA University Archivist in the UCLA Library Special Collections, for their inspiration to conduct this research and their invaluable advice in the process of writing the paper. This research was supported by the Shanghai Planning Office of Philosophy and Social Science (Project No.2019ETQ004) and Fundamental Research Funds for the Central Universities (Project No.2018ECNU-HWFW036) from the government of China. 


\section{REFERENCES}

Abrizah, A. and Thelwall, M. 2014. Can the impact of non-western academic books be measured? An investigation of Google Books and Google Scholar for Malaysia. Journal of the Association for Information Science and Technology, Vol. 65, no.12: 2498-2508. Available at: https://doi.org/10.1002/asi.23145.

Chen, S. and Wang, C. 2008. Who has published what in East Asian studies? An analysis of publishers and publishing trends. Library Resources \& Technical Services, Vol. 52, no.1: 33-41. Available at:https://doi.org/10.5860//rts.52n1.33.

Economic and Social Research Council. 2018. What is impact? Available at: https://esrc.ukri.org/research/impact-toolkit/what-is-impact/.

Erfanmanesh, M., Noorhidawati, A., and Abrizah, A. 2019. What can Bookmetrix tell us about the impact of Springer Nature's books. Scientometrics, Vol.121, no.1:521-536.

Gimenez-Toledo, E., Manana-Rodriguez, J. and Sivertsen, G. 2017. Scholarly book publishing: Its information sources for evaluation in the social sciences and humanities. Research Evaluation, Vol. 26, no.2: 91-101. Available at: https://doi.org/10.1093/reseval/rvx007.

Gorraiz, J., Purnell, P.J. and Glanzel, W. 2013 Opportunities for and limitations of the Book Citation Index, Journal of the Association for Information Science \& Technology, Vol. 64, no.7: 1388-1398. Available at: https://doi.org/10.1002/asi.22875.

Halevi, G., Nicolas, B., and Bar-llan, J. 2016. The complexity of measuring the impact of books. Publishing Research Quarterly, Vol.32, no.3: 187-200. Available at: https://doi.org/10.1007/s12109-016-9464-5.

Jokić, M., Mervar, A., and Mateljan, S. 2019. Comparative analysis of book citations in social science journals by Central and Eastern European authors. Scientometrics, Vol.120, no.3: 1005-1029. Available at: https://doi.org/10.1007/s11192-019-03176-y.

Kousha, K., Thelwall, M. and Rezaie, S. 2011. Assessing the citation impact of books: The role of Google Books, Google Scholar, and Scopus, Journal of the Association for Information Science \& Technology, Vol.62, no.11: 2147-2164. Available at: https://doi.org/10.1002/asi.21608.

Kousha, K. and Thelwall, M. 2016a. An automatic method for assessing the teaching impact of books from online academic syllabi, Journal of the Association for Information Science \& Technology, Vol. 67, no.12: 2993-3007. Available at: https://doi.org/10.1002/asi.23542.

Kousha, K. and Thelwall, M. 2016b. Can Amazon.com reviews help to assess the wider impacts of books? Journal of the Association for Information Science \& Technology, Vol. 67, no.3: 566-581. Available at: https://doi.org/10.1002/asi.23404.

Kousha, K. and Thelwall, M. 2018. Can Microsoft Academic help to assess the citation impact of academic books?. Journal of Informetrics, Vol. 12, no.3: 972-984. Available at: https://doi.org/10.1016/j.joi.2018.08.003.

Labbé, C. 2010. Ike Antkare one of the great stars in the scientific firmament, International Society for Scientometrics \& Informetrics Newsletter, Vol.6, no.3: 48-52. Available at: http://www.issi-society.org/media/1126/newsletter22.pdf. 
Mas-Bleda, A. and Thelwall, M. 2018. Do prestigious Spanish scholarly book publishers have more teaching impact?. Aslib Journal of Information Mangement, Vol.70, no.6SI: 673-690. Available at: https://doi.org/10.1108/AJIM-04-2018-0094.

Priem, J., Taraborelli, D., Groth, P. and Neylon, C. 2010. Altmetrics: A manifesto. Available at: http://altmetrics.org/manifesto/.

Tatalovich, R., and Frendreis, J. 2019. Winning awards and gaining recognition: An impact analysis of APSA section book prizes. Social Science Journal, Vol.56, no.3: 316-323. Available at: https://doi.org/10.1016/j.soscij.2018.07.006.

Torres-Salinas, D. and Moed, H.F. 2009. Library Catalog Analysis as a tool in studies of social sciences and humanities: An exploratory study of published book titles in Economics. Journal of Informetrics, Vol. 3, no.1: 9-26. Available at: https://doi.org/10.1016/j.joi.2008.10.002.

Torres-Salinas, D., Robinson-Garcia, N., Jimenez-Contreras, E. and Delgado Lopez-Cozar, E. 2012. Towards a "Book Publishers Citation Reports". First approach using the "Book Citation Index". Revista Espanola De Documentacion Cientifica, Vol.35, no.4: 615-624. Available at: https://doi.org/10.3989/redc.2012.4.1010.

Torres-Salinas, D., Robinson-Garcia, N., Miguel Campanario, J., and Delgado Lopez-Cozar, E. 2014. Coverage, field specialisation and the impact of scientific publishers indexed in the Book Citation Index. Online Information Review, Vol.38, no.1: 24-42. Available at: https://doi.org/10.1108/OIR-10-2012-0169.

Torres-Salinas, D., Robinson-Garcia, N. and Gorraiz, J. 2017. Filling the citation gap: measuring the multidimensional impact of the academic book at institutional level with PlumX, Scientometrics, Vol. 113, no.3: 1371-1384. Available at: https://doi.org/10.1007/s11192-017-2539-z.

Wikipedia. 2018. Sinology. Available at: https://en.wikipedia.org/wiki/Sinology.

Wang, K., Liu, X. and Han, Y. 2019. Exploring Goodreads reviews for book impact assessment. Journal of Informetrics, Vol.13, no.3: 874-886. Available at:https://doi.org/10.1016/j.joi.2019.07.003.

White, H.D., Boell, S.K., Yu, H., Davis, M. and Cole, F.T.H. 2009. Libcitations: A measure for comparative assessment of book publications in the humanities and social sciences, Journal of the Association for Information Science \& Technology, Vol. 60, no.6: 1083-1096. Available at:https://doi.org/10.1002/asi.21045.

Zuccala, A., Verleysen, F.T., Cornacchia, R. and Engels, T.C.E. 2015. Altmetrics for the humanities Comparing Goodreads reader ratings with citations to history books, Aslib Journal of Information Management, Vol. 67, no.3: 320-336. Available at:https://doi.org/10.1108/AJIM-11-2014-0152. 